\title{
Factors Effecting Students' Lifelong Learning in Higher Education
}

\author{
Hande DINNDAR ${ }^{1}$, Mustafa BAYRAKCI ${ }^{2}$
}

\author{
* PhD, Ankara University, Department of Adult Education, handedindar@hotmail.com \\ **Asst. Prof. Dr., Sakarya University, Education Faculty, mustafabayrakci@hotmail.com
}

\begin{abstract}
More and more the concept of lifelong learning gains importance in both governmental and educational perspectives. As higher education is dominant force in education, learners' experiences in higher education will have ramifications for the practice of teaching and learning at all levels. In this study it is aimed to identify who is the lifelong learner through literature review then a scale was conducted to undergraduate university students. After determining the factors and dimensions of the scale, ANOVA and t-test have been made to specify if there is any difference between undergraduate university students in terms of their gender, age, programs they study, grade, family income. The results show that gender doesn't lead any changes among factors effecting lifelong learning of students in general, except the dimension "Curiosity" in which female students with higher points differ significantly from male students. Also factors effecting undergraduate students' lifelong learning significantly differ according to programme they study in favor of students at literature branches while age differences, grade differences and family income differences don't lead any significant change.
\end{abstract}

Keywords: lifelong learner, lifelong learning, student, higher education

\section{Introduction}

In this century, most of the countries aim to have citizens who are lifelong learners which can be induced from several policy papers whether directly related with lifelong learning or not. Especially international organizations such as European Union (EU) and Organization for Economic Cooperation and Development (OECD) and United Nations Education Science and Culture Organization (UNESCO) have significant contributions to provide opportunities for individuals to become lifelong learners. Also in Turkey, there are many policy papers emphasizing the importance of the lifelong learning and the necessity of having lifelong learning citizens. There is a duty to learn but also a corresponding right to do so, and these are a consequence of citizenship (Lawson, 2007).

Higher education merits special study because of its particular importance in helping to develop and implement a system of lifelong education and they also play a major role in the training of teachers, where they provide not only knowledge, but also theoretical principles (such as belief in the importance of lifelong learning) and practical experience. In addition, university teachers can serve as important role models by employing teaching strategies that are oriented to learning throughout life. As higher education is dominant force in education, learners' experiences in higher education will have ramifications for the practice of teaching and learning at all levels (Knapper \& Cropley, 2000).

The term lifelong learning is one that requires careful definition because it is used widely in contemporary educational discourse and has a range of meanings (Crick, Broadfoot and Claxton; 2004) and definitions of lifelong learning often include those who follow educational programmes within and outwith academic institutions, as well as those who learn spontaneously, so including 'lifewide' as well as 'lifelong' learning (Loads, 2007). There are many definitions of lifelong learning which in common agrees on that learning is a process and there are significant changes in every part of the life which affects people's lives continuously so an individual should keep learning and be keen on changing with learning through lifespan. Lifelong learning is defined by some in broadly humanistic terms as a way of empowering people for active engagement with important personal, social and global issues. Others take a more narrowly instrumental approach, prioritizing the attainment of skills and qualifications in order to improve economic competitiveness and productivity (Loads, 2007).

In Turkey there is not enough study on lifelong learning. Poyraz and Titrek (2013) examined how to develop lifelong learning and Titrek, Zafer Güneş and Sezen (2013) suggested a model about lifelong learning in higher education. In this study, factors effecting lifelong learning of undergraduate university students at education faculty of Sakarya University is aimed to be identified so as to have an idea about future teachers' lifelong learning tendencies. Teachers are the key factor in lifelong learning communities because they can guide many more to become lifelong learners. That's why providing future teachers with 
lifelong learning profiles is important. After conducting Factors Effecting Lifelong Learning Scale, it is aimed to specify differences between undergraduate university students' lifelong learner profile;

a) Specify any gender differences in factors effecting lifelong learning of undergraduate university students

b) Specify any age differences in factors effecting lifelong learning of undergraduate university students

c) Specify any programs differences in factors effecting lifelong learning of undergraduate university students

d) Specify any grade differences in factors effecting lifelong learning of undergraduate university students

e) Specify any family income differences in factors effecting lifelong learning of undergraduate university students

\section{Who is the lifelong learner?}

Lifelong learners are most desired in this century but who is the lifelong learner and what is required to become lifelong learner remain uncertain. Making lifelong learning part of one's life fosters a sense of personal empowerment and, increased self-esteem. It ensures continued growth and intellectual stimulation, leading to a more fulfilling, enjoyable, and enriched lifestyle (Mazaheri \& Fadavi, 2011). Also lifelong learning may be presented as a duty, placing the responsibility for learning on individuals, exposing them to the social and economic risks of non-participation, and expecting them to pay the cost themselves (Loads, 2007). Alternatively, it may be viewed as a right, with the responsibility on the state to ensure equality of learning opportunity in order to promote social inclusion and equity (Loads, 2007).

Lifelong learners require appropriate guidance, counseling and support at their different ages and stages of life and careers in order for them to become successful learners (Walters, 2008). Lifelong learning takes place at all times and in all places, as (Laal, 2011):

- Age 0-5 years: A lot of learning takes place during this age group to provide a foundation for future learning habits and talents. This is probably the age with the highest amount of informal learning as children imitate almost everything from parents, peers and their environment.

- Age 6-24 years: Learning at this age group primarily takes place in educational institutions, from primary and secondary to tertiary levels. Family life, social organizations, religious institutions, and mass media have a role in learning during this time.

- Age 25-60 years: This age group can learn informally through the use of instructional media, mostly from their occupations, work-places, colleagues, touring, mass media, information technologies, environment and nature. Adults learn from experiences and problem solving. They therefore need continuous development of intellect, capability and integrity.

- Age 60+ years: Elderly people can learn a great deal from activities suitable to their age e.g. art, music, sports for the elderly, handicrafts and social work. They can also carry out voluntary work in community organizations, clubs and associations.

Lifelong learning will not only develop individuals to become responsible to themselves and their communities, but understand and involve actively at all levels of their societies. If countries are to see lifelong learning develop further, then everyone's patterns of behavior, needs to change including: individuals, employers, and the providers of learning and qualifications (Laal, 2011). Lifelong learners acquire their beliefs, knowledge and understanding that they need, beyond the ones they already have, in all the highways and byways of the cognitive world (Aspin \& Chapman, 2012).

The true lifelong learner perceives of his or her learning as an integral experience (Visser, 2012). Lifelong learners take all possible opportunities to learn without being put off by difficulties. Lifelong learners must turn to their own resources - their interests, ambitions, motivations, habits, circumstances, opportunities, friends, family and associates (Skilbeck, 2012). Lifelong learners are able to choose a life they have reason to value. This involves more than access, and includes participation and success and positive learner identity formation (Walker, 2007). To foster lifelong learners, supportive learning cultures are needed, not only in learning groups but also inside the minds of participants. Such cultures actively maintain positive emotions and tackle blocks, enabling participants to develop emotional resilience (Evison, 2008).

Lifelong learners have a positive attitude towards learning and about themselves as learners. They are commonly described in terms of their curiosity, interest and enthusiasm for learning (Bryce, 2006). They perceive failures as providing information about what does not work (Evison, 2008). Students who have developed the capacity to question, reason and evaluate can be typified as (Bryce, 2006):

- being continually aware of change and variety; 
- being aware that not all change and variety is necessarily positive in intent or outcome;

- never being satisfied with the status quo but constantly on the lookout for novelty, innovation and new ways of doing things;

- continually wanting to improve procedure and processes, and update skills as well as information; and

- being as critical of their own views as they are of the views of others

Candy and others suggest that the lifelong learner would exhibit the following qualities or characteristics to some degree (Candy, Crebert, \& O'Leary, 1994):

- An inquiring mind

o a love of learning;

0 a sense of curiosity;

o a critical spirit;

o comprehension and monitoring and self-evaluation;

- Helicopter vision

0 a sense of interconnectedness of fields;

0 an awareness of how knowledge is created in at least one field of study, and an understanding of the methodological and substantive limitations of that field;

o breadth of vision;

- Information literacy

o knowledge of major current resources available in at least one field of study;

0 ability to frame researchable questions in at least one field of study;

0 ability to locate, evaluate, manage and use information in a range of contexts;

0 ability to retrieve information using a variety of media;

0 ability to decode information in a variety of forms: written, statistical, graphs, charts, diagrams and table;

o critical evaluations of information;

- A sense of personal agency

o a positive concept of oneself as capable and autonomous;

o self-organisation skills (time management, goal-setting etc);

- A repertoire of learning skills

o knowledge of one's own strengths, weakness and preferred learning style;

0 range of strategies for learning in whatever context one finds oneself; and

0 an understanding of the differences between surface and deep level learning.

The lifelong learner (Cropley \& Knapper, 1983): (1) should be strongly aware of the relationship between learning and real life; (2) should be aware of the need for lifelong learning; (3) should be highly motivated to carry on a process of lifelong learning; (4) should possess a self-concept favourable to lifelong learning; and (5) should possess the necessary skills for lifelong learning. These skills include the ability to (a) set personal objectives in a realistic way; (b) apply existing knowledge in an effective manner; (c) evaluate one's own learning efficiently; (d) locate information when it becomes apparent that there is a need to do so; (e) use different and effective learning strategies in appropriate settings (in groups or alone, with or without a teacher, and so on); and (f) employ a variety of different learning tools, such as books, the media, self-instructional kits. Lifelong learners who are primarily engaged in autonomous self-learning (Evers, 2007):

- Experience regarded as a problem

- Observations and reflections during which relevant data, thoughts, ideas about the problem are assimilated

- Formulate possible solutions, i.e. hypotheses

- Test each hypothesis by action/research until a solution is discovered

- Assimilate solution

- Experience no longer a problem

Effective lifelong learners are able to (Kirby, Knapper, Lamon, \& Egnatoff, 2010); set goals, apply appropriate knowledge and skills, engage in self-direction and self-evaluation, locate required information, and adapt their learning strategies to different conditions. Bryce, (2006) describes lifelong learners as who;

- have developed competence with a range of print and electronic media and are able to engage effectively with their available range of learning opportunities. 
- are 'information literate': that is, they are able to recognize the need for information; they can use available technologies with confidence; they know how to access specific and relevant information sources through these technologies; and they know how to organise all the stuff once it is obtained.

- are able to synthesise, analyse and (above all) evaluate this raw information.

- have developed a sound general knowledge, various bodies of specialised knowledge according to their interests, as well as a clear sense of the interconnectedness of fields of knowledge.

- are able to make connections between learning in school and out of school and aim for a deep understanding in as many relevant fields as possible.

- have 'strategic foresight' - the ability to read patterns and trends so as to be pre-emptive about the skills and information needed in an environment of constant change.

- have a number of learning skills which enable them to identify what it is they need to do to successfully engage in a learning task and to transfer what they have learnt to other situations.

\section{Method}

\section{Participants}

The participants in this study were 413 undergraduate students at Sakarya University. The participants were recruited by visiting classes and asking for volunteers. Characteristics of the sample are shown in Table 1.

Table 1. Descriptive Statistics of the Sample

\begin{tabular}{lll}
\hline & $\mathbf{N}$ & $\mathbf{\%}$ \\
\hline Gender & 242 & 58,6 \\
Female & 171 & 41,4 \\
Male & & \\
Chronological Age & 206 & 49,9 \\
20 and below & 207 & 50,1 \\
21 and above & & \\
Grade & 55 & 13,3 \\
1 & 264 & 63,9 \\
2 & 49 & 11,9 \\
3 & 45 & 10,9 \\
4 & & \\
Programmes & 356 & 86,2 \\
Math-Science & 57 & 13,8 \\
Literature & & \\
Income & 40 & 9,7 \\
$0-750$ TL & 159 & 38,5 \\
750-1500 TL & 140 & 33,9 \\
1500-2500 TL & 74 & 17,9 \\
2500 TL and above & & \\
\hline
\end{tabular}

According to the Table 1, sample of the study consists of $242(58,6 \%)$ female, $171(41,4 \%)$ male in total 413 students. $207(50,1)$ of students are 21 years old and above. Also $264(63,9 \%)$ of students are second grade while $356(86,2 \%)$ of students study at Math-Science programmes. $159(38,5 \%)$ of students have approximately 750 to $1500 \mathrm{tl}$ income.

\section{Instruments}

A scale which was developed by Poyraz (2014) was used to collect data for the study. The first part of the questionnaire includes remarks and personal data and the second part includes Factors Effecting Lifelong Learning Scale developed by Poyraz (2014). Factors Effecting Lifelong Learning Scale consists of four factors which are "Curiosity", "Openness to Learning", "Access to Information and Information Literacy" and "Self-direction and Self-evaluation". Participants responded on five point Likert scales, ranging from 1 (strongly disagree) to 5 (strongly agree). Internal consistency (Cronbach alpha) was .93 and for each factor, the Cronbach-Alpha coefficient was calculated as $0.88,0.81,0,81$ and 0.86 , respectively. Later the data collected for this study analyzed whether there is a significant difference of 
factors effecting lifelong learning of students according to their genders, ages, programmes of study and grades.

\section{Procedure and Data Analysis}

The students completed the survey in two ways: paper format during class or take home and return. The data was analyzed through SPSS 11.5 package program. Results and discussions have been made according to the reached data. In the analyses of the data, mean, standard deviation, t-test and One-way ANOVA analysis were used.

\section{Findings}

In this part of the study through the data collected with Factors Effecting Lifelong Learning Scale, results are presented to show if there is a significant difference of factors effecting lifelong learning of students according to their genders, ages, programmes of study and grades. Descriptive statistics for the factors effecting lifelong learning scale are shown in Table 2 .

Table 2. Descriptive Statistics for the Factors Effecting Lifelong Learning of Undergraduate Students

\begin{tabular}{|c|c|c|c|}
\hline Lifelong Learning & $\mathbf{M}$ & SD & Max. \\
\hline \multicolumn{4}{|l|}{ Curiosity } \\
\hline 1. I research what makes me curious. & 4,19 & ,86 & \\
\hline 2. I love learning especially when I want to learn. & 4,38 & 91 & \\
\hline 3. I am a curious person. & 3,98 & 94 & \\
\hline 4. I feel a necessity to learn about what makes me curious. & 4,14 & ,80 & \\
\hline 5. I feel a need to question what makes me curious. & 4,05 & ,85 & \\
\hline 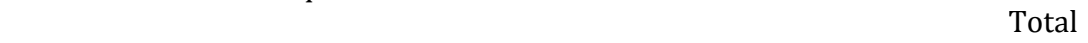 & 20,74 & 3,62 & 25 \\
\hline \multicolumn{4}{|l|}{ Openness to Learning } \\
\hline 6. I use different strategies while learning. & 3,68 & ,86 & \\
\hline 7. I change my strategy when I have difficulties. & 3,68 & ,86 & \\
\hline 8. I can find a way to learn no matter what is the situation. & 3,81 & 90 & \\
\hline 9. I know how I can learn in a best way. & 3,69 & 85 & \\
\hline 10. I know how I won't learn. & 3,81 & ,9 & \\
\hline 11. I am with people from whom I can learn something. & 3,88 & ,92 & \\
\hline 12. I can learn with others. & 3,96 & 89 & \\
\hline 13. It is important to keep learning after graduation. & 3,84 & ,99 & \\
\hline 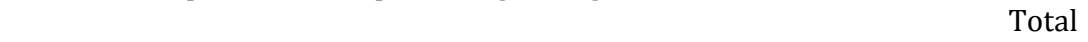 & 30,35 & 4,72 & 40 \\
\hline \multicolumn{4}{|l|}{ Access to Information and Information Literacy } \\
\hline $\begin{array}{l}\text { 14. I can reach what I am looking for from different sources (internet, media, } \\
\text { and library). }\end{array}$ & 4,30 & 87 & \\
\hline 15. I use different sources to reach information. & 4,23 & ,84 & \\
\hline 16. I can read graphics and schemes and comment statistical data. & 4,00 & ,93 & \\
\hline 17. I can evaluate the data whether they are valid and reliable or not. & 4,06 & ,84 & \\
\hline \multirow[t]{2}{*}{$\begin{array}{l}\text { 18. I can use the data in different contexts and can show them with graphics } \\
\text { or schemes. }\end{array}$} & 3,88 & 81 & \\
\hline & 20,48 & 3,28 & 25 \\
\hline Total & & & \\
\hline \multicolumn{4}{|l|}{ Self-direction and Self-evaluation } \\
\hline 19. I don't need help when I make a plan. & 3,78 & ,84 & \\
\hline 20. I am qualified enough to evaluate myself. & 3,62 & ,96 & \\
\hline 21. I have abilities to lead my own learning. & 3,86 & ,85 & \\
\hline 22. I am sufficient to direct myself. & 3,82 & ,86 & \\
\hline 23. I have skills to evaluate my own learning. & 3,87 & 81 & \\
\hline 24. I have skills to arrange my own learning. & 3,95 & 80 & \\
\hline Total & 22,90 & 3,98 & 30 \\
\hline TOTAL & 94 & 13,22 & 120 \\
\hline
\end{tabular}

Considering generally the students perceptions towards lifelong learning, students agree more with statements which are "I love learning especially when I want to learn." (M=4,38), "I can reach what I am looking for from different sources (internet, media, and library)." (M=4,3), "I use different sources to reach information" $(M=4,23)$, "I research what makes me curious" $(M=4,19)$, " I feel a necessity to learn about what makes me curious" $(M=4,14)$, "I can evaluate the data whether they are valid and reliable or not" $(M=4,06)$. On the other hand they agree less with statements which are "I know how I won't 
learn" $(M=3,81)$, "I don't need help when I make a plan" $(M=3,78)$, "I know how I can learn in a best way" $(M=3,69)$, "I use different strategies while learning" $(M=3,68)$, "I change my strategy when I have difficulties" (M=3,68), "I am qualified enough to evaluate myself" $(M=3,62)$.

Table 3 presents the results of the independent-samples t-test conducted to determine gender differences of factors effecting undergraduate students' lifelong learning scores. The total of factors effecting lifelong learning scores of undergraduate students shows that the female undergraduate students' mean score is 95,15 and the male undergraduate students mean score is 93,53 . $t$-value between the scores of the two groups is $1,223(\mathrm{p}>0,05)$ so factors effecting undergraduate students' lifelong learning don't significantly differ according to gender. Furthermore, the dimensions of the factors effecting undergraduate students' lifelong learning scale are also investigated for gender differences.

Table 3. Gender differences in undergraduate students

\begin{tabular}{|c|c|c|c|c|c|c|c|}
\hline Factors & Gender & $\mathbf{N}$ & $\overline{\mathbf{X}}$ & sd & df & $\mathbf{t}$ & $\mathbf{p}$ \\
\hline \multirow[t]{2}{*}{ Curiosity } & Female & 242 & 20,89 & 3,40 & 411 & 1,038 & 034 \\
\hline & Male & 171 & 20,52 & 3,92 & & & \\
\hline \multirow[t]{2}{*}{ Openness to Learning } & Female & 242 & 30,77 & 4,56 & 411 & 2,153 & ,066 \\
\hline & Male & 171 & 29,76 & 4,90 & & & \\
\hline \multirow{2}{*}{$\begin{array}{l}\text { Access to Information and } \\
\text { Information Literacy }\end{array}$} & Female & 242 & 20,64 & 3,17 & 411 & 1,199 & 261 \\
\hline & Male & 171 & 20,25 & 3,43 & & & \\
\hline \multirow{2}{*}{$\begin{array}{l}\text { Self-direction } \\
\text { Self-evaluation }\end{array}$} & Female & 242 & 22,83 & 4,02 & 411 &,- 419 & 984 \\
\hline & Male & 171 & 23,00 & 3,94 & & & \\
\hline \multirow[t]{2}{*}{ TOTAL } & Female & 242 & 95,15 & 12,87 & 411 & 1,223 & 154 \\
\hline & Male & 171 & 93,53 & 13,68 & & & \\
\hline
\end{tabular}

For the dimension "Curiosity", the female students' mean score is 20,89, and male students' mean score is 20,52 . t-value between the scores of the two group is $1,013(\mathrm{p}<0,05)$. These results indicate that there is a significant difference between female and male undergraduate students' scores of factors effecting lifelong learning in favor of the females. For the next dimension "Openness to Learning", the female students' mean score is 30,77 , and male students' mean score is 29,76 . t-value between the scores of the two group is $2,153(\mathrm{p}<0,05)$. It can be said according to these results that there is a significant difference between female and male undergraduate students' scores and female undergraduate students' scores are higher than the male students. The following dimensions are "Access to Information and Information Literacy" ( $t=1,199 ; p=, 261)$ and "Self-direction and Self-evaluation" $(t=-, 419 ; p=, 984)$ and there is no significant difference at the $\mathrm{p}<.05$ level in these dimensions.

Table 4 presents the results of the independent-samples t-test conducted to determine program differences in undergraduate students' scores of factors effecting lifelong learning. The total undergraduate students' scores of factors effecting lifelong learning shows that the math-science undergraduate students' mean score is 94,40 and the literature undergraduate students mean score is 95 . $t$-value between the scores of the two groups is,$- 317(\mathrm{p}<0,05)$ so factors effecting lifelong learning of undergraduate students' significantly differ according to programme they study in favor of students at literature programmes. Furthermore, the dimensions of the factors effecting lifelong learning scale are also investigated for programme differences.

Table 4. Program differences in undergraduate students

\begin{tabular}{|c|c|c|c|c|c|c|}
\hline Factors & Program & $\mathbf{X}$ & sd & df & $\mathbf{t}$ & p \\
\hline \multirow[t]{2}{*}{ Curiosity } & MS & 20,75 & 3,56 & 411 & ,245 & 074 \\
\hline & $\mathrm{L}$ & 20,63 & 4,05 & & & \\
\hline \multirow[t]{2}{*}{ Openness to Learning } & MS & 30,21 & 4,60 & 411 & $-1,476$ & 312 \\
\hline & $\mathrm{L}$ & 31,21 & 5,40 & & & \\
\hline Access to Information & MS & 20,50 & 3,23 & 411 & ,411 & ,266 \\
\hline Information Literacy & $\mathrm{L}$ & 20,31 & 3,63 & & & \\
\hline \multirow[t]{2}{*}{ Self-direction and Self-evaluation } & MS & 22,91 & 3,88 & 411 & 134 & 096 \\
\hline & $\mathrm{L}$ & 22,84 & 4,61 & & & \\
\hline \multirow[t]{2}{*}{ TOTAL } & MS & 94,40 & 12,78 & 411 &,- 317 & 047 \\
\hline & $\mathrm{L}$ & 95 & 15,82 & & & \\
\hline
\end{tabular}


According to Table 4, for the dimension "Curiosity", the students at math-science programmes mean score is 20,75 , and students at literature programmes mean score is 20,63. t-value between the scores of the two group is, $245(\mathrm{p}<0,05)$. These results indicate that there is a significant difference between students at math-science and literature programmes in factors affecting lifelong learning scores in favor of the math and science students. For the other dimensions "Openness to Learning" $(t=-1,476 ; p=, 312)$, "Access to Information and Information Literacy" ( $t=, 411 ; p=, 266)$ and "Self-direction and Self-evaluation" $(\mathrm{t}=, 134 ; \mathrm{p}=, 0,96)$ and there is no significant difference at the $\mathrm{p}<.05$ level in these dimensions.

Table 5 presents the results of the independent-samples t-test conducted to determine age differences in factors effecting lifelong learnings of undergraduate students. The total factors effecting lifelong learning scores of undergraduate students shows that 20 and younger undergraduate students' lifelong learner profile mean score is 92,86 and 21 and older undergraduate students mean score is 96,095. t-value between the scores of the two groups is $-2,492(p>0,05)$ so factors effecting undergraduate students' lifelong learning don't significantly differ according to age differences.

Table 5. Age differences in undergraduate students

\begin{tabular}{|c|c|c|c|c|c|c|c|}
\hline Factors & Age & $\mathbf{N}$ & $\mathbf{X}$ & sd & df & $\mathbf{t}$ & $\mathbf{p}$ \\
\hline \multirow[t]{2}{*}{ Curiosity } & 20 and below & 206 & 20,21 & 3,86 & 411 & $-2,973$ & ,132 \\
\hline & 21 and above & 207 & 21,26 & 3,3 & & & \\
\hline \multirow[t]{2}{*}{ Openness to Learning } & 20 and below & 206 & 29,82 & 4,88 & 411 & $-2,298$ & ,448 \\
\hline & 21 and above & 207 & 30,88 & 4,51 & & & \\
\hline Access to Information and & 20 and below & 206 & 20,08 & 3,43 & 411 & $-2,449$ & 667 \\
\hline \multirow{3}{*}{$\begin{array}{l}\text { Information Literacy } \\
\text { Self-direction and Self-evaluation }\end{array}$} & 21 and above & 207 & 20,87 & 3,09 & & & \\
\hline & 20 and below & 206 & 22,74 & 4,02 & 411 &,- 815 & 610 \\
\hline & 21 and above & 207 & 23,06 & 3,95 & & & \\
\hline \multirow[t]{2}{*}{ TOTAL } & 20 and below & 206 & 92,86 & 13,75 & 411 & $-2,492$ & ,754 \\
\hline & 21 and above & 207 & 96,09 & 12,5 & & & \\
\hline
\end{tabular}

Furthermore, the dimensions of the scale are also investigated for age differences. For the dimension "Curiosity" ( $t=,-2,973 ; \mathrm{p}=, 132)$, "Openness to Learning" ( $\mathrm{t}=-2,298 ; \mathrm{p}=, 448)$, "Access to Information and Information Literacy" ( $\mathrm{t}=-2,449 ; \mathrm{p}=, 667)$ and "Self-direction and Self-evaluation" $(\mathrm{t}=-, 815 ; \mathrm{p}=, 610)$ and there is no significant difference at the $\mathrm{p}<.05$ level in these dimensions.

Table 6 presents ANOVA results of grade differences for factors effecting lifelong learning of undergraduate students. The total factors effecting lifelong learning scores and the dimensions of the factors effecting lifelong learning are $(\mathrm{F}=1,703 ; \mathrm{p}=, 166)$; "Curiosity" $(\mathrm{F}=1,421 ; \mathrm{p}=, 236)$, "Openness to Learning" ( $F=1,862 ; p=, 135)$, "Access to Information and Information Literacy" $(F=1,178 ; p=, 318)$ and "Self-direction and Self-evaluation" ( $F=, 971 ; p=, 406)$.

Table 6. ANOVA results of grade differences

\begin{tabular}{|c|c|c|c|c|c|c|}
\hline Factors & Grade & $\bar{x}$ & sd & df & $\mathbf{F}$ & $\mathbf{p}$ \\
\hline \multirow{4}{*}{ Curiosity } & 1 & 20,12 & 3,41 & & 1,421 &, 236 \\
\hline & 2 & 20,66 & 3,9 & 3 & & \\
\hline & 3 & 21,12 & 3,04 & 409 & & \\
\hline & 4 & 21,51 & 2,56 & & & \\
\hline \multirow{4}{*}{ Openness to Learning } & 1 & 29,14 & 4,29 & & 1,862 & 135 \\
\hline & 2 & 30,37 & 4,97 & 3 & & \\
\hline & 3 & 31,22 & 4,29 & 409 & & \\
\hline & 4 & 30,73 & 3,94 & & & \\
\hline \multirow{4}{*}{$\begin{array}{l}\text { Access to Information and } \\
\text { Information Literacy }\end{array}$} & 1 & 20,18 & 2,41 & & 1,178 & 318 \\
\hline & 2 & 20,34 & 3,58 & 3 & & \\
\hline & 3 & 21,02 & 3,09 & 409 & & \\
\hline & 4 & 21,04 & 2,42 & & & \\
\hline \multirow{4}{*}{$\begin{array}{l}\text { Self-direction } \\
\text { Self-evaluation }\end{array}$} & 1 & 22,52 & 3,68 & & 971 & ,406 \\
\hline & 2 & 22,77 & 4,27 & 3 & & \\
\hline & 3 & 23,59 & 3,3 & 409 & & \\
\hline & 4 & 23,40 & 3,17 & & & \\
\hline \multirow{4}{*}{ TOTAL } & 1 & 91,98 & 10,89 & & 1,703 & 166 \\
\hline & 2 & 94,17 & 14,39 & 3 & & \\
\hline & 3 & 96,95 & 11,35 & 409 & & \\
\hline & 4 & 96,68 & 9,68 & & & \\
\hline
\end{tabular}


As indicated in Table 6 there is no significant difference in factors effecting lifelong learning of undergraduate students scores regarding the grade differences at the $\mathrm{p}<.05$.

Table 7 presents ANOVA results of family income differences for factors effecting lifelong learning of undergraduate students. The total factors effecting lifelong learning scores $(F=1,706 ; p=, 165)$ and the dimensions of the factors effecting lifelong learning are; "Curiosity" ( $F=1,864 ; p=, 135)$, "Openness to Learning" ( $F=1,543 ; p=, 203)$, "Access to Information and Information Literacy" $(F=, 195 ; p=, 900)$ and "Self-direction and Self-evaluation" (F=1,706; $p=, 165)$.

Table 7. ANOVA results of family income differences

\begin{tabular}{|c|c|c|c|c|c|c|}
\hline Factors & Family Income & $\bar{x}$ & sd & df & $\mathbf{F}$ & $\mathbf{p}$ \\
\hline \multirow[t]{4}{*}{ Curiosity } & $0-750 \mathrm{TL}$ & 20,12 & 4,54 & 3 & 1,864 & ,135 \\
\hline & $750-1500 \mathrm{TL}$ & 20,82 & 3,95 & 409 & & \\
\hline & $1500-2500 \mathrm{TL}$ & 20,42 & 3,15 & & & \\
\hline & 2500 TL and above & 21,5 & 3,08 & & & \\
\hline \multirow[t]{4}{*}{ Openness to Learning } & $0-750 \mathrm{TL}$ & 29,85 & 5,30 & 3 & 1,543 & 203 \\
\hline & $750-1500 \mathrm{TL}$ & 30,36 & 5,17 & 409 & & \\
\hline & $1500-2500 \mathrm{TL}$ & 29,96 & 4,34 & & & \\
\hline & 2500 TL and above & 31,33 & 3,98 & & & \\
\hline Access to Information and & $0-750 \mathrm{TL}$ & 20,35 & 4,30 & 3 & 195 & ,900 \\
\hline \multirow[t]{3}{*}{ Information Literacy } & $750-1500 \mathrm{TL}$ & 20,47 & 3,27 & 409 & & \\
\hline & $1500-2500 \mathrm{TL}$ & 20,39 & 3,22 & & & \\
\hline & 2500 TL and above & 20,72 & 2,81 & & & \\
\hline Self-direction & $0-750 \mathrm{TL}$ & 22,97 & 4,29 & 3 & 1,986 & 115 \\
\hline \multirow[t]{3}{*}{ Self-evaluation } & $750-1500 \mathrm{TL}$ & 22,69 & 4,15 & 409 & & \\
\hline & $1500-2500 \mathrm{TL}$ & 22,6 & 3,86 & & & \\
\hline & 2500 TL and above & 23,9 & 3,57 & & & \\
\hline \multirow[t]{4}{*}{ TOTAL } & $0-750 \mathrm{TL}$ & 93,3 & 15,74 & 3 & 1,706 & 165 \\
\hline & $750-1500 \mathrm{TL}$ & 94,36 & 14,42 & 409 & & \\
\hline & $1500-2500 \mathrm{TL}$ & 93,37 & 11,75 & & & \\
\hline & 2500 TL and above & 97,47 & 11,36 & & & \\
\hline
\end{tabular}

According to Table 7 there is no significant difference in factors effecting lifelong learning of undergraduate students scores regarding the family income differences at the $\mathrm{p}<.05$.

\section{Discussion}

In this study Factors Effecting Undergraduate University Students' Lifelong Learning at Education Faculty of Sakarya University was examined. The main purpose of this study is to show whether there is significant difference between undergraduate university students' lifelong learner profiles according to their gender, age, programs they study, grade, family income. Gender doesn't lead any changes among lifelong learner profiles of students in general, except the dimension "Curiosity" in which female students with higher points differ significantly from male students. Also undergraduate students' lifelong learner profiles significantly differ according to programme they study in favor of students at literature programmes while age differences, grade differences and family income differences don't lead any significant change. To improve undergraduate students' lifelong learning competences, university teachers should adopt teaching approaches consistent with lifelong learning however those teaching approaches may clash with the more traditional functions of universities. But teachers both have to be lifelong learners themselves and have to make students have positive lifelong learning profiles. In fact most university teachers already do this in their role as scholars and researchers, where updating knowledge and skills is an essential part of remaining current in the field. In the case of teaching, however, there is often little ongoing professional development which may negatively affect future teachers (Sharma, 2004).

Considering generally the students perceptions towards lifelong learning, students agree more with statements which are "I love learning especially when I want to learn.", "I can reach what I am looking for from different sources (internet, media, and library).", "I use different sources to reach information" , "I research what makes me curious", " I feel a necessity to learn about what makes me curious", "I can evaluate the data whether they are valid and reliable or not". So it can be inferred that students have positive tendencies towards the dimensions of curiosity and access to information and information literacy. On the other hand they agree less with statements which are "I know how I won't learn", "I don't 
need help when I make a plan", "I know how I can learn in a best way", "I use different strategies while learning", "I change my strategy when I have difficulties", "I am qualified enough to evaluate myself". It can be suggested that students should be encouraged to openness to learning and self-direction and self-evaluation.

One of the most important roles of universities in lifelong learning which highly depends on the performance of university teachers in initial training of teachers is providing future teachers with lifelong learning profiles and abilities to being role model for their students. Therefore factors effecting lifelong learning of undergraduate university students who are future teachers are analyzed. Future teachers should be equipped with the knowledge of how to promote lifelong learning skills in class, too.

There is a need to provide lifelong learners in this age for countries' welfare as it has been emphasized through many policy papers. To achieve this goal, university teachers should be aware of their roles and they should equip university students with lifelong learning profiles. While universities would not abandon the transfer of professional knowledge and skills, these would now be offered within a new pluralist environment that would ensure experiences such as (Stevenson, 2000): exposure to a variety of mindsets, not just the dominant one; an understanding of human consciousness, and creating alternative tools for thought and change; thinking across a range of mindsets, clearly declaring the epistemological assumptions; critically questioning personal assumptions and conventional values; exploring and assessing new life patterns and cultures, and social inventions generally integrating theory with practice, and quantitative with qualitative inquiry; interdisciplinary understanding; lifelong learning; design and flexible delivery of learning to suit local conditions, specific cultures and a variety of learners; intercultural and intergenerational exchange and sensitivity and long-term thinking (futures) and anticipation.

\section{References}

Aspin, D. N., \& Chapman, J. D. (2012). Towards a Philosophy of Lifelong Learning. In D. N. Aspin, J. Chapman, K. Evans, \& R. Bagnall (Eds.), International Handbook of Lifelong Learning (pp. 3-36). Dordrecht, Heidelberg, London, New York: Springer.

Bryce, J. (2006). Schools and Lifelong Learners. In J. Chapman, P. Cartwright, \& E. J. McGilp, Lifelong Learning, Participation and Equity (pp. 243-263). Dordrecht: Springer.

Candy, P. C., Crebert, G., \& O'Leary, J. (1994). Developing Lifelong Learners through Undergraduate Education. National Board of Employement, Education and Training. Canberra: Australian Government Publishing Service.

Crick, Broadfoot, \& Claxton. (2004). Developing an Effective Lifelong Learning Inventory: the ELLI Project. Assessment in Education: Principles, Policy \& Practice, 11(2), 247-272.

Cropley, A. J., \& Knapper, C. K. (1983). Higher Education and the Promotion of Lifelong Learning. Studies in Higher Education, 8(1), 15-21.

European Commission. (2013). Supporting teacher competence development for better learning outcomes.

Evers, C. W. (2007). Lifelong Learning and Knowledge. In D. N. Aspin (Ed.), Philosophical Perspectives on Lifelong Learning (pp. 173-188). Dordrecht: Springer.

Evison, R. (2008). Changing to learning cultures that foster lifelong learners. In P. Sutherland, \& J. Crowther (Eds.), Lifelong Learning: Concepts and contexts (pp. 94-107). Oxon: Routledge.

Kirby, J., Knapper, C., Lamon, P., \& Egnatoff, W. (2010). Development of a scale to measure lifelong learning. International Journal of Lifelong, 3(29), 291-302.

Knapper, C. K., \& Cropley, A. J. (2000). Lifelong Learning in Higher Education. London: Kogan Page.

Laal, M. (2011). Lifelong learning: What does it mean? Procedia - Social and Behavioral Sciences(28), 470-474.

Lawson, K. (2007). Lifelong Learning: Conceptual and Ethical Issues. In D. N. Aspin (Ed.), Philosophical Perspectives on Lifelong Learning (pp. 109-113). Dordrecht: Springer.

Loads, D. (2007). Effective Learning Advisers' perceptions of their role in supporting lifelong learning. Teaching in Higher Education, 2(12), 235-245.

Mazaheri, M. M., \& Fadavi, M. s. (2011). The role of Educational Technology in Lifelong Learning. Procedia Social and Behavioral Sciences(28), 842-844.

Poyraz, H., \& Titrek, O. (2013). Türkiye'de Hayat Boyu Öğrenmenin Geliştirilmesi (Development of Lifelong Learning in Turkey). Abant İzzet Baysal Üniversitesi Eğitim Fakültesi Dergisi, 131, 115-131.

Poyraz, H. (2014). Öğretmenlerin yaşam boyu öğrenmelerini etkileyen faktörler ile kurumları tarafindan desteklenme algıları arasındaki ilişki. Master Thesis: Sakarya University.

Sharma, T. C. (2004). Meaning of Lifelong Learning. Delhi: SARUP\&SONS. 
Skilbeck, M. (2012). No Royal Road: Mapping the Curriculum for Lifelong Learning. In D. N. Aspin, J. Chapman, K. Evans, \& R. Bagnall (Eds.), Second International Handbook of Lifelong Learning (pp. 499-520). Dordrecht, Heidelberg, London, New York: Springer.

Stevenson, T. (2000). Mindshift to the future. Futures, 32(5), 487-491.

Titrek, O., Zafer Güneș, D. \& Sezen, G. (2013). "Yükseköğretim ve Yaşam Boyu Öğrenme: Bir Model Önerisi" (Higher Education and Lifelong Learning: A Model Suggestion). ICQH 2013, 12-14 December 2013, SAU Congress Centre. http://www.icqh.net/index.php?page=program

Visser, J. (2012). Refl ections on a Definition: Revisiting the Meaning of Learning. In D. N. Aspin, J. Chapman, K. Evans, \& R. Bagnall (Eds.), Second International Handbook of Lifelong Learning (pp. 163-180). Dordrecht, Heidelberg, London, New York.

Walker, M. (2007). Widening Participation in Higher Education: Lifelong Learning as Capability. In D. N. Aspin (Ed.), Philosophical Perspectives on Lifelong Learning (pp. 131-147). Dordrecht: Springer.

Walters, S. (2008). Realizing a lifelong learning higher education institution. In P. Sutherland, \& J. Crowthe (Eds.), Lifelong Learning: Concepts and contexts (pp. 71-81). Oxon: Routledge. 